\title{
USULAN PERANCANGAN ULANG TATA LETAK PABRIK PADA PT. XYZ
}

\author{
Nofi Erni ${ }^{1}$, Lamto Widodo ${ }^{2}$,Y unike Poala ${ }^{2}$ \\ ${ }^{1}$ Program Studi Teknik Industri Universitas Esa Unggul \\ ${ }^{2}$ Program Studi Teknik Industri Universitas Tarumanagara \\ e-mail: hemilton9181@ymail.com
}

\begin{abstract}
ABSTRAK
PT. XYZ merupakan perusahaan industri manufaktur yang bergerak dalam bidang pembuatan kabel listrik bertegangan rendah.Permasalahan yang ditemukan berkaitan dengan pengaturan tata letak.Tujuan penelitian adalah menghasilkan rancangan tata letak pabrik baru yang efektif dan efisien agar dapat meminimumkan jarak, waktu,dan biaya pemindahan bahan.Perencanaan tata letak dibuat menggunakan pendekatan Systematic Layout Planning.Pengolahan data dilakukan dengan menguji data-data yang telah dikumpulkan untuk digunakan dalam pembuatan diagram alir, Operation Process Chart, Flow Process Chart, routing sheet, Multi Product Process Chart, luas lantai produksi, dan Material Handling Planning Sheet. Metode pendekatan SLP yang digunakan dalam perancangan antara lain: From-To Chart, Activity Relationship Chart, Activity Relationship Diagram, Area Allocation Diagram, dan Material Handling Evaluation Sheet. Selanjutnya, dilakukan analisa hasil dan pembuatan model simulasi tata letak pabrik awal dan tata letak pabrik usulan dengan software ProModel.Pada perbandingan antara tata letak pabrik awal dan tata letak pabrik usulan, diperoleh efisiensi jarak pemindahan bahan sebesar $52 \%$ dan biaya pemindahan bahan sebesar $72 \%$. Sedangkan berdasarkan hasil report dari running model simulasi, diperolehwaktu proses produksi (waktu operasi dan waktu pemindahan bahan) pada tata letak pabrik usulanlebih efisien 37\% dibandingkan dengan tata letak pabrik awal.
\end{abstract}

Kata Kunci: Tata Letak Pabrik, Pemindahan Bahan, Systematic Layout Planning, Simulasi

\begin{abstract}
PT.XYZ is a manufacturing company that produces a low voltage power cables. Problems found in this study are about the plant layout. The research objective is to produce a new plant layout design of effective and efficient to minimize the distance, time, and material handling costs. Planning the layout made using the approach of System Layout Planning (SLP). Data processing is done by examining data collected for use in the manufacture of flow charts, Chart Operation Process, Process Flow Chart, routing sheet, Multi-Product Process Chart, production floor area, and Planning Sheets Material Handling. SLP method approach used in the design include: From-To Chart, Relationship Chart Activity, Activity Relationship Diagram, Diagram Allocation Area, Material Handling and Evaluation Sheet. Furthermore, the results of analysis and simulation modeling of initial plant layout and the layout of the proposed plant with Promodel software. In the comparison between the initial plant layout and the layout of the proposed plant, the efficiency is obtained at a distance of $51 \%$ reduction of material handling and material handling cost savings of $72 \%$. Based on the results of running the simulation model, obtained production process time (time of operation and materials handling time) on the layout of the proposed plant $37 \%$ more efficient than the original factory layout.
\end{abstract}

Keywords: Plant Layout, Material Handling, Systematic Layout Planning, Simulation

\section{PENDAHULUAN}

Perancangan tata letak yang baik pada umumnya akan memberikan kontribusi yang positif dalam optimalisasi proses operasi perusahaan dan pada akhirnya akan menjaga kelangsungan seta keberhasilan sebuah perusahaan. Perancangan tata letak pabrik meliputi perencanaan dan pengaturan letak mesin, peralatan, aliran bahan, dan operator yang bekerja pada masing-masing stasiun kerja. Jika disusun dengan baik, maka jalannya operasi kerja akan menjadi lebih efektif and efisien.PT. XYZmerupakan sebuah perusahaan industri manufaktur yang memproduksi kabel listrik bertegangan rendah. Saat 
ini kondisi tata letak pabrik belum cukup efisien dengan ditemukannya permasalahan pada rancangan tata letak pabrik yang digunakan. Ketidakteraturan tata letak mesin menyebabkan panjangnya jarak lintasan pemindahan bahan antaraktivitas proses produksi, sehingga biaya produksi yang dikeluarkan oleh perusahaan menjadi kurang efisien. Pada penelitian dilakukan wawancara dan pengambilan data dari pihak perusahaan, serta pengamatan langsung di perusahaan, dengan pembatasan produk yang diamati selama dilakukan penelitian adalah pada 2 jenis kabel yaitu kabel NYA $1.5 \mathrm{~mm}^{2}$ dan kabel NYM 2 x $1.5 \mathrm{~mm}^{2}$.Tujuan dilakukan penelitian adalah untuk menganalisa tata letak pabrik secara aktual, menghasilkan rancangan tata letak pabrik baru yang lebih baik dari tata letak yang digunakan oleh perusahaan saat ini melalui pendekatan Systematic Layout Planning (SLP), sehingga tercapai efektivitas dan efisiensi pada lintasan aktivitas proses produksi yang dapat meminimumkan jarak pemindahan bahan.Manfaat dari penelitian yang dilakukan di PT. XYZini adalah memperoleh bahan pertimbangan dalam pengambilan keputusan perancangan tata letak pabrik baru bagi perusahaan melalui kajian yang dilakukan pada penelitian ini dan mendapatkan saran sebagai bahan evaluasi untuk pengembangan produksi untuk masa-masa mendatang.

\section{Tata Letak Pabrik (Plant Layout)}

\section{TINJAUAN PUSTAKA}

Tata letak pabrik adalah tata cara pengaturan fasilitas-fasilitas pabrik sebagai penunjang kelancaran proses produksi. Tujuan utama dari perencanaan tata letak pabrik adalah mengatur area kerja dan segala fasilitas produksi yang paling ekonomis untuk mencapai produksi yang aman dan nyaman [1].Terdapat 4 tipe tata letak yang secara umum digunakan dalam perancangan tata letak antara lain tata letak produk, tata letak proses, tata letak tetap (fixed layout), dan group technology-based layout.[2]

\section{Pengukuran Waktu}

Pengukuran waktu baku merupakan kriteria dari pengukuran kerja.Untuk mendapatkan waktu baku, terlebih dahulu perlu diperhitungkan waktu siklus dan waktu normal. Pengukuran waktu untuk mendapatkan waktu baku dilakukan dengan melakukan pengujian kecukupan data, pengujian keseragaman data, dan perhitungan waktu standar (waktu baku). Pada perhitungan waktu baku terdapat pertimbangan tambahan faktor penyesuaian dan kelonggaran (allowance). [1]

\section{Systemastic Layout Planning}

SLP merupakan suatu pendekatan dari perancangan tata letak sistematik, sehingga memiliki aturan tata langkah yang jelas dalam perancangan tata letak[3].Dengan berorientasi pada 5 elemen dasar tata letak yaitu produk, kuantitas, proses, sistem pendukung, dan waktu, diharapkan susunan lantai produksi benar-benar sesuai dengan kebutuhan perusahaan.

\section{Perhitungan Jumlah Mesin}

Perhitungan jumlah mesin dilakukan dengan menggunakan lembar pengurutan produksi (routing sheet)dan Multi Product Process Chart (MPPC).

\section{Peta-Peta Kerja}

Peta-peta kerja merupakan suatu alat sistematis dan jelas untuk berkomunikasi secara luas.Pada peta kerja, terdapat lambang yang melambangkan aktivitas produksi operasi, pemeriksaan, transportasi, penyimpanan, menunggu, dan aktivitas gabungan. Beberapa 
peta kerja antara lain diagram aliran, peta proses operasi (Operation Process Chart), peta aliran proses (Flow Process Chart), dan peta dari-ke (From-To Chart).Salah satu peta kerja yang seringkali digunakan sebagai pendukung peta proses yaitu diagram aliran. Diagram aliran adalah catatan grafis dari langkah-langkah proses yang dibuat di atas tata letak suatu tempat yang sedang di kaji [3].

\section{Material Handling Planning Sheet (MHPS)}

MHPSadalah tabel yang digunakan untuk menghitung besarnya biaya dari tiap-tiap penanganan atau pemindahan bahan berdasarkan jarak dan peralatan pemindahan bahan yang digunakan.Jarak pemindahan bahan didapatkan dengan menggunakan data luas tiap kelompok mesin pada perhitungan luas lantai produksi teoritis. [3]

\section{Peta Keterkaitan Diagram (Activity Relationship Chart)}

Activity Relationship Chart adalah teknik ideal untuk merencanakan keterkaitan antara setiap kelompok aktivtas yang saling berkaitan. Huruf-huruf A, E, I, O, U pada ARC menunjukkan derajat hubungan kedekatan antarlokasi. [1]

\section{Diagram Keterkaitan Kegiatan (Activity Relationship Diagram)}

ARD merupakan diagram balok yang menunjukkan pendekatan keterkaitan kegiatan sebagai suatu model aktivitas tunggal.Hubungan kedekatan pada tabel penyesuaian skala prioritas FTC sebagai berikut:

Hubungan A : berada pada bagian sisi mesin yang bersangkutan.

Hubungan E: berjarak maksimum 1 kotak.

Hubungan I: berjarak maksimum 2 kotak.

Hubungan O: berjarak maksimum 3 kotak.

\section{Area Allocation Diagram (AAD)}

Tujuan dibuat AAD adalah merancang ruang produksi yang efisien dalam satu kesatuan terpadu dan mengatur letak stasiun kerja yang efisien pada lantai produksi dengan memperhatikan hubungan kedekatan yang telah ditentukan dalam ARD.

\section{Material Handling Evaluation Sheet (MHES)}

MHPS adalah tabel perhitungan biaya penanganan bahan yang digunakan untuk mengevaluasi tata letak yang dihasilkan. Tabel MHES memiliki format dan rumus perhitungan yang sama dengan tabel MHPS.

\section{Simulasi}

ProModel adalah sebuah software simulasi berbasis windows yang khusus di desain untuk mensimulasikan masalah-masalah yang ada pada industri manufaktur dimana produk yang diproses adalah produk-produk yang dapat dihitung. [4]

\section{METODE PENELITIAN}

Data yang dikumpulkan dari perusahaan terdiri dari data bahan baku produksi produk, hasil produksi perusahaan, mesin-mesin yang digunakan di pabrik, waktu produksi hasil pengamatan secara langsung di pabrik, luas lahan perusahaan, persentase efisiensi pabrik, target produksi perusahaan, dan data mengenai pemindahan bahan (material handling). Data yang telah dikumpulkan selanjutnya diolah dengan menggunakan metode-metode antara lainpeta proses operasi (OPC), peta aliran proses (FPC), routing sheet, MPPC, dan MHPS. 
Setelah tahap pengumpulan data dan pengolahan data, maka tahap selanjutnya adalah pembuatan rancangan tata letak pabrik, meliputi pembuatan From-To Chart, perhitungan skala prioritas, pembuatan ARC dan ARD, perancangan ulang tata letak pabrik baru berdasarkan AAD, serta pembuatan MHES. Tata letak pabrik baru hasil rancangan ulang, selanjutnya akan di analisa dan dibuatsimulasimenggunakan software ProModel. Penarikan kesimpulan dan saran dilakukan sebagai tahap akhir dalam metodologi penelitian. Pada Gambar 1 berikut ini dapat dilihat diagram alir metodologi penelitian.

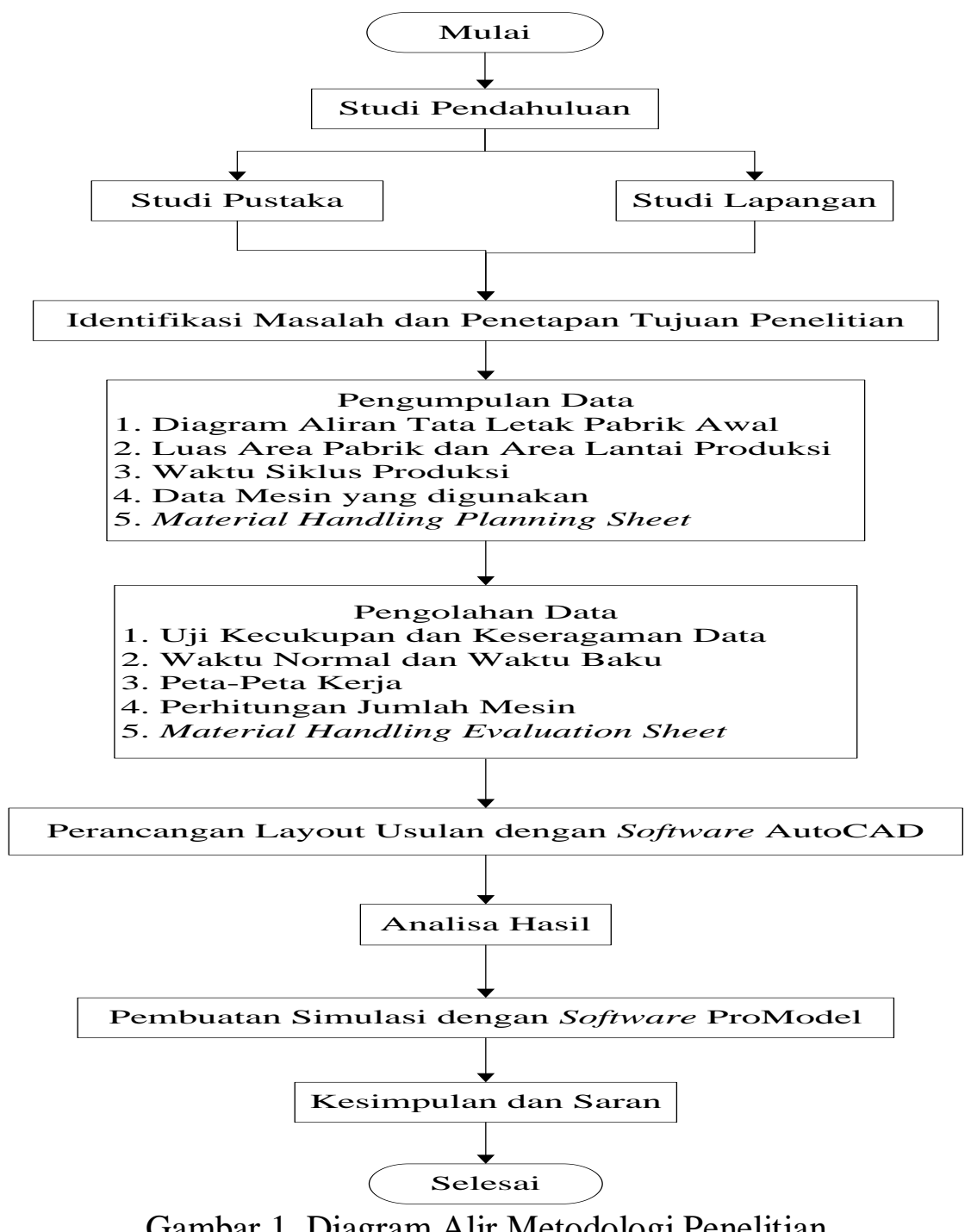

Gambar 1. Diagram Alir Metodologi Penelitian

\section{HASIL DAN PEMBAHASAN}

Berdasarkan data yang telah dikumpulkan akan dilakukan perhitungan waktu baku yang akan digunakan untuk pembuatan peta proses operasi (Operation Process Chart). OPC adalah suatu diagram yang menggambarkan langkah-langkah proses yang akan dialami bahan baku berkaitan denganaktivitas operasi dan pemeriksaan. Pada Gambar 2 dapat dilihat peta proses operasi kabel NYM $2 \times 1.5 \mathrm{~mm}^{2}$. 


\section{PETA PROSES OPERASI}

Produk: Kabel NYM 2 x $1.5 \mathrm{~mm}^{2}$

Tanggal : 20 Mei 2013

Dipetakan oleh: Yunike Poala

Tembaga dan PVC

Plastik pembungkus kabel, tali,

O-1

Proses Insulation dan Pemeriksaan 68 detik

PVC (filler), PVC (selubung)

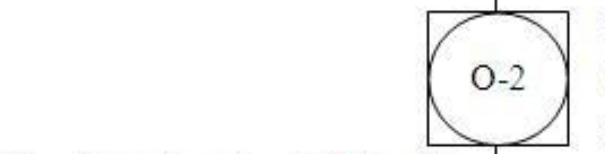

Proses Cabling-Filler-Sheathing-

Coiling dan Pemeriksaan

301.3 detik

karung

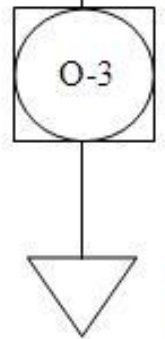

Proses Packing dan Pemeriksaan 150.2 detik

Penvimpanan kabel NYM di Gudang Barang Jadi

\begin{tabular}{|c|r|r|}
\hline Aktivitas & Jumlah & Waktu (detik) \\
\hline Operasi dan Pemeriksaan & 3 & 519.5 \\
\hline
\end{tabular}

\begin{tabular}{|c|c|}
\hline \multicolumn{2}{|l|}{ RINGKASAN } \\
\hline Keterangan & Jumlah \\
\hline Operasi & - \\
\hline C) Transportasi & 5 \\
\hline$\square$ Pemeriksaan & - \\
\hline D Penundaan & - \\
\hline$\nabla$ Penyimpanan & 2 \\
\hline$\square$ Operasi dan Pemeriksaan & 3 \\
\hline Jumlah Jarak Pemindahan Bahan (meter) & 188 \\
\hline Jumlah Waktu Baku (detik) & 523.8 \\
\hline
\end{tabular}

Gambar 2. Peta Proses Operasi Kabel N

Selanjutnya dibuat peta aliran proses (flow processs chart) yang merupakan kombinasi antara peta proses operasi dengan peta proses untuk tiap komponen produk. Peta ini menggambarkan gambaran grafis paling lengkap dari keseluruhan proses. 
Nama Komponen:Kabel NYM

\section{Flow Process Chart}

Uraian Proses: Aktivitas proses produksi

bahan baku hingga menjadi barang jadi

per 1 roll (50 meter) kabel.

Departemen: Produksi

Pabrik: PT. XYZ

Tanggal : 20 Mei 2013

Dicatat oleh: Yunike Poala

\begin{tabular}{|c|c|c|c|c|c|c|c|c|c|}
\hline \multirow{2}{*}{ No. } & \multirow{2}{*}{ Uraian Metode Sekarang } & \multicolumn{5}{|c|}{ Simbol } & \multirow{2}{*}{$\begin{array}{c}\text { Cara } \\
\text { Pemindahan } \\
\end{array}$} & \multirow{2}{*}{ Jarak } & \multirow{2}{*}{$\begin{array}{l}\text { Waktu } \\
\text { Baku }\end{array}$} \\
\hline & & 0 & ㄷ) & $\square$ & $\nabla$ & 0 & & & \\
\hline 1 & $\begin{array}{l}\text { Penyimpanan bahan baku kabel } \\
\text { NYM berupa tembaga dan PVC } \\
\text { di gudang bahan baku. }\end{array}$ & & & & $\nabla$ & & - & - & - \\
\hline 2 & $\begin{array}{l}\text { Pemindahan bahan bakudari } \\
\text { gudang bahan baku ke area } \\
\text { gudang bahan baku sementara. }\end{array}$ & & 다 & & & & Forklift & $\begin{array}{l}36 \\
\text { meter }\end{array}$ & $\begin{array}{l}0.3 \\
\text { detik }\end{array}$ \\
\hline 3 & $\begin{array}{l}\text { Penyimpanan bahan baku kabel } \\
\text { NYM di area gudang bahan baku } \\
\text { sementara. }\end{array}$ & & & & $\nabla$ & & - & - & - \\
\hline 4 & $\begin{array}{l}\text { Pemindahan bahan baku (tembaga } \\
\text { dan PVC) dari area gudang bahan } \\
\text { baku sementara ke mesin extruder } \\
\text { untuk proses insulation. }\end{array}$ & & 도 & & & & $\begin{array}{l}\text { Hand Pallet } \\
\text { dan lori }\end{array}$ & $\begin{array}{l}45 \\
\text { meter }\end{array}$ & $\begin{array}{l}0.8 \\
\text { detik }\end{array}$ \\
\hline 5 & $\begin{array}{l}\text { Aktivitas proses insulation dan } \\
\text { pemeriksaan. }\end{array}$ & & & & & 》 & - & - & $\begin{array}{l}68 \\
\text { detik }\end{array}$ \\
\hline 6 & $\begin{array}{l}\text { Pemindahan bobbin kabel insul } \\
\text { dari mesin extruder ke mesin } \\
\text { tandem. }\end{array}$ & & 牙 & & & & Hand Pallet & $\begin{array}{l}51 \\
\text { meter }\end{array}$ & $\begin{array}{l}1.1 \\
\text { detik }\end{array}$ \\
\hline 7 & $\begin{array}{l}\text { Aktivitas proses pada mesin } \\
\text { tandem yaitu proses cabling- } \\
\text { filling-sheathing-coiling dan } \\
\text { pemeriksaan. }\end{array}$ & & & & & & - & - & $\begin{array}{l}301.3 \\
\text { detik }\end{array}$ \\
\hline 8 & $\begin{array}{l}\text { Pemindahan pallet bermuatan } 100 \\
\text { roll kabel dari mesin tandem ke } \\
\text { area packingII. }\end{array}$ & & 穴 & & & & Hand Pallet & $\begin{array}{l}8 \\
\text { meter }\end{array}$ & $\begin{array}{l}0.7 \\
\text { detik }\end{array}$ \\
\hline 9 & $\begin{array}{l}\text { Aktivitas proses packing kabel } \\
\text { (pembungkusan dengan plastik, } \\
\text { pengemasan ke dalam karung, } \\
\text { dan penjahitan karung) dan } \\
\text { pemeriksaan. }\end{array}$ & & & & & & - & - & $\begin{array}{l}150.2 \\
\text { detik }\end{array}$ \\
\hline 10 & $\begin{array}{l}\text { Pemindahan pallet bermuatan } 20 \\
\text { karung ( } 120 \text { roll kabel) dari area } \\
\text { packing II ke gudang barang jadi. }\end{array}$ & & 도 & & & & Hand Pallet & $\begin{array}{l}48 \\
\text { meter }\end{array}$ & $\begin{array}{l}1.4 \\
\text { detik }\end{array}$ \\
\hline 11 & $\begin{array}{l}\text { Penyimpanan kabel NYM di } \\
\text { gudang barang jadi. }\end{array}$ & & & & $\nabla$ & & - & - & - \\
\hline
\end{tabular}

\section{Gambar 3. FPC Kabel NYM di PT. XYZ}

Perhitungan jumlah mesin dengan membandingkan antara jumlah mesin teoritis dan jumlah mesin aktual pada lantai produksi diperlukan dengan tujuan agar diketahuikecukupan jumlah mesin secara aktual.Tabel perbandingan antara jumlah mesin teoritis yang dibutuhkan dan jumlah mesin aktual di pabrik dapat dilihat pada Tabel 1 . 
Tabel 1. Perbandingan Antara Jumlah Mesin Teoritis dan Jumlah Mesin Aktual

\begin{tabular}{ccccccccc}
\hline No. & Nama Mesin & $\begin{array}{c}\text { Jumlah } \\
\text { Mesin } \\
\text { Teoritis }\end{array}$ & $\begin{array}{c}\text { Pembulatan } \\
\text { Jumlah } \\
\text { mesin } \\
\text { Teoritis }\end{array}$ & $\begin{array}{c}\text { Jumlah } \\
\text { Mesin } \\
\text { Aktif }\end{array}$ & $\begin{array}{c}\text { Jumlah } \\
\text { Mesin } \\
\text { Cadangan }\end{array}$ & $\begin{array}{c}\text { Jumlah } \\
\text { Kekurangan } \\
\text { Mesin }\end{array}$ & $\begin{array}{c}\text { Jumlah } \\
\text { Kelebihan } \\
\text { Mesin }\end{array}$ & $\begin{array}{c}\text { Jumlah } \\
\text { Mesin } \\
\text { Rusak }\end{array}$ \\
\hline $\begin{array}{l}\text { Mesin } \text { extruder } \\
\text { (proses } \\
\text { ekstrusi kabel } \\
\text { jadi) }\end{array}$ & 6.08 & 6 & 6 & 0 & 0 & 0 & 0 \\
\hline $\begin{array}{l}\text { Mesin } \text { extruder } \\
\text { (proses } \\
\text { produksi kabel } \\
\text { insul) }\end{array}$ & 3.04 & 3 & 3 & 0 & 0 & 0 & 0 \\
\hline 3 & Mesin tandem & 3.06 & 3 & 3 & 0 & 0 & 0 & 0 \\
\hline 4 & Mesin coiling & 6.12 & 6 & 6 & 0 & 0 & 0 & 0 \\
\hline 5 & Area packing & 2.04 & 2 & 2 & 0 & 0 & 0 & 0 \\
\hline
\end{tabular}

Rancangan tata letak pabrik barudibuat berdasarkan AAD yang dipilih yaitu AAD inflow.Dimana dalam proses perancangan ulang tata letak pabrik, terdapat beberapa langkah yang perlu dilakukan yaitu dengan membuat From-To Chart (FTC), skala prioritas mesin,Activity Relationship Chart (ARC), Activity Relationship Diagram (ARD), Area Allocation Diagram (AAD) serta Material Handling Evaluation Sheet (MHES). Hasil rancangan tata letak pabrik baru akan di analisa dan dibuat simulasi agar dapat diketahui perbandingan antara tata letak awal dan tata letak usulan.

\section{Pembuatan From-To Chart (FTC)}

Tabel2. FTC Biaya Kabel NYM

\begin{tabular}{|c|c|c|c|c|c|c|c|c|}
\hline Dari & $\mathrm{Ke}$ & $\begin{array}{c}\text { Gudang } \\
\text { Bahan } \\
\text { Baku }\end{array}$ & $\begin{array}{c}\text { Area } \\
\text { Gudang } \\
\text { Bahan } \\
\text { Baku } \\
\text { Sementara }\end{array}$ & $\begin{array}{l}\text { Mesin } \\
\text { Extruder }\end{array}$ & $\begin{array}{l}\text { Mesin } \\
\text { Tandem }\end{array}$ & $\begin{array}{c}\text { Area } \\
\text { Packing }\end{array}$ & $\begin{array}{c}\text { Gudang } \\
\text { Barang } \\
\text { Jadi }\end{array}$ & Jumlah \\
\hline 1 & Gudang Bahan Baku & & $2.127,69$ & & & & & $2.127,69$ \\
\hline 3 & $\begin{array}{l}\text { Area Gudang Bahan } \\
\text { Baku Sementara }\end{array}$ & & & $5.319,22$ & & & & $5.319,22$ \\
\hline 5 & Mesin Extruder & & & & $24.113,78$ & & & $24.113,78$ \\
\hline 7 & Mesin Tandem & & & & & $5.831,44$ & & $5.831,44$ \\
\hline 9 & Area Packing & & & & & & $29.314,79$ & $29.314,79$ \\
\hline 11 & Gudang Barang Jadi & & & & & & & 0 \\
\hline & Jumlah & 0 & 0 & $2.127,69$ & $5.319,22$ & $24.113,78$ & $5.831,44$ & $29.314,79$ \\
\hline
\end{tabular}

FTC yang dibuat terdiri dari FTC biaya, FTC inflow, dan FTC outflow.Pada pembuatan FTC biaya, data yang digunakan adalah berasal dari hasil perhitungan biaya MHPS. Tabel FTC yang terpilih untuk digunakan adalah FTC biaya dan FTC inflow kabel NYM 2 x $1.5 \mathrm{~mm}^{2}$ yang dapat dilihat pada Tabel 2 dan Tabel 3 berikut ini. 
Tabel 3. FTC Inflow Kabel

\begin{tabular}{|c|c|c|c|c|c|c|c|c|}
\hline Dari & $\mathrm{Ke}$ & $\begin{array}{c}\text { Gudang } \\
\text { Bahan } \\
\text { Baku }\end{array}$ & $\begin{array}{c}\text { Area } \\
\text { Gudang } \\
\text { Bahan } \\
\text { Baku } \\
\text { Sementara }\end{array}$ & $\begin{array}{c}\text { Mesin } \\
\text { Extruder }\end{array}$ & $\begin{array}{c}\text { Mesin } \\
\text { Tandem }\end{array}$ & $\begin{array}{c}\text { Area } \\
\text { Packing }\end{array}$ & $\begin{array}{c}\text { Gudang } \\
\text { Barang } \\
\text { Jadi }\end{array}$ & Jumlah \\
\hline 1 & Gudang BahanBaku & & 1 & & & & & 1 \\
\hline 3 & Area Gudang Bahan Baku Sementara & & & 1 & & & & 1 \\
\hline 5 & Mesin Extruder & & & & 1 & & & 1 \\
\hline 7 & Mesin Tandem & & & & & 1 & & 1 \\
\hline 9 & Area Packing & & & & & & 1 & 1 \\
\hline 11 & Gudang Barang Jadi & & & & & & & 0 \\
\hline & Jumlah & 0 & 1 & 1 & 1 & 1 & 1 & 5 \\
\hline
\end{tabular}

Perhitungan FTC biaya dan FTC inflowpada proses dari gudang bahan baku ke area gudang bahan baku sementara adalah sebagai berikut:

a. FTC biaya

Pemindahan data dari MHPS ke FTC biaya.

b. FTC inflow

Nilai sel FTC inflow $=\frac{2.127,69}{2.127,69}=1$

\section{Perhitungan Skala Prioritas}

Berdasarkan tabel hubungan kedekatan antarmesin dengan range nilai, maka dibuat tabel skala prioritas FTC inflow. Angka-angkapada FTC inflow dan diurutkan mulai dari yang paling besar hingga yang paling kecil, selanjutnya dikelompokkan untuk masuk pada hubungan A, E, I, O, U. Angka bernilai sama dimasukkan berderet pada hubungan yang sama.Berikut pada Tabel 4 di bawah ini dapat dilihat tabel skala prioritas FTC inflow kabel NYM.

Tabel 4.Skala Prioritas FTC Inflow Kabel NYM

\begin{tabular}{llcllll}
\hline No. & \multicolumn{1}{c}{ Nama Mesin } & A & E & I & O & U \\
\hline 1 & Gudang Bahan Baku & - & - & - & - & - \\
3 & Area Gudang Bahan Baku Sementara & $1^{1}$ & - & - & - & - \\
5 & Mesin Extruder & $3^{1}$ & - & - & - & - \\
7 & Mesin Tandem & $5^{1}$ & - & - & - & - \\
9 & Area Packing & $7^{1}$ & - & - & - & \\
11 & Gudang Barang Jadi & $9^{1}$ & - & - & - \\
\hline
\end{tabular}

\section{Pembuatan Activity Relationship Chart (ARC)}

\begin{tabular}{|c|c|c|}
\hline 1 & Gudang Bahan Baku & \\
\hline 3 & Area Gudang Bahan Baku Sementara & \\
\hline 5 & Mesin Extruder & \\
\hline 7 & Mesin Tandem & \\
\hline 9 & Area Packing & \\
\hline 11 & Gudang Barang Jadi & \\
\hline
\end{tabular}

Gambar 4. ARC Kabel NYM 
Simbol huruf pada peta keterkaitan kegiatan merupakan simbol untuk menunjukkan derajat hubungan kedekatan antarlokasi.Selain simbol, terdapat nomor yang merupakan alasan penjelasan mengapa simbol digunakan.Pada Gambar 4 berikut ini dapat dilihat ARC kabel NYM

\section{Pembuatan Area Relationship Diagram (ARD)}

Setiap aktivitas proses produksi pada ARD dianggap sebagai aktivitas tunggal, tidak memiliki penekanan ruang. Dalam pembuatan ARD perlu adanya penyesuaian skala prioritas FTC.Penyesuaian skala prioritas FTCInflow Kabel NYM dibuat dalam bentuk tabel yang dapat dilihat pada Tabel 5berikut ini.

Tabel5. Penyesuaian Skala Prioritas FTC Inflow Kabel NYM

\begin{tabular}{lrllll}
\hline No. & \multicolumn{1}{c}{ A } & E & I & O & U \\
\hline 1 & 3 & - & - & - & - \\
3 & 1,5 & - & - & - & - \\
5 & 3,7 & - & - & - & - \\
7 & 5,9 & - & - & - & - \\
9 & 7,11 & - & - & - & - \\
11 & 9 & - & - & - & - \\
\hline
\end{tabular}

Pada iterasi pertama ARD inflow tidak ditemukan error, makatelah dapat digunakan untuk pembuatan tahap selanjutnya yaitu AAD.Hasil pembuatan ARD inflow dengan iterasi pertama dapat dilihat pada Gambar5 berikut ini.

\begin{tabular}{|l|l|l|l|l|l|}
\hline 1 & 3 & 5 & 7 & 9 & 11 \\
\hline
\end{tabular}

Gambar 5. ARD InflowKabel NYM

\section{Pembuatan Area Allocation Diagram (AAD)}

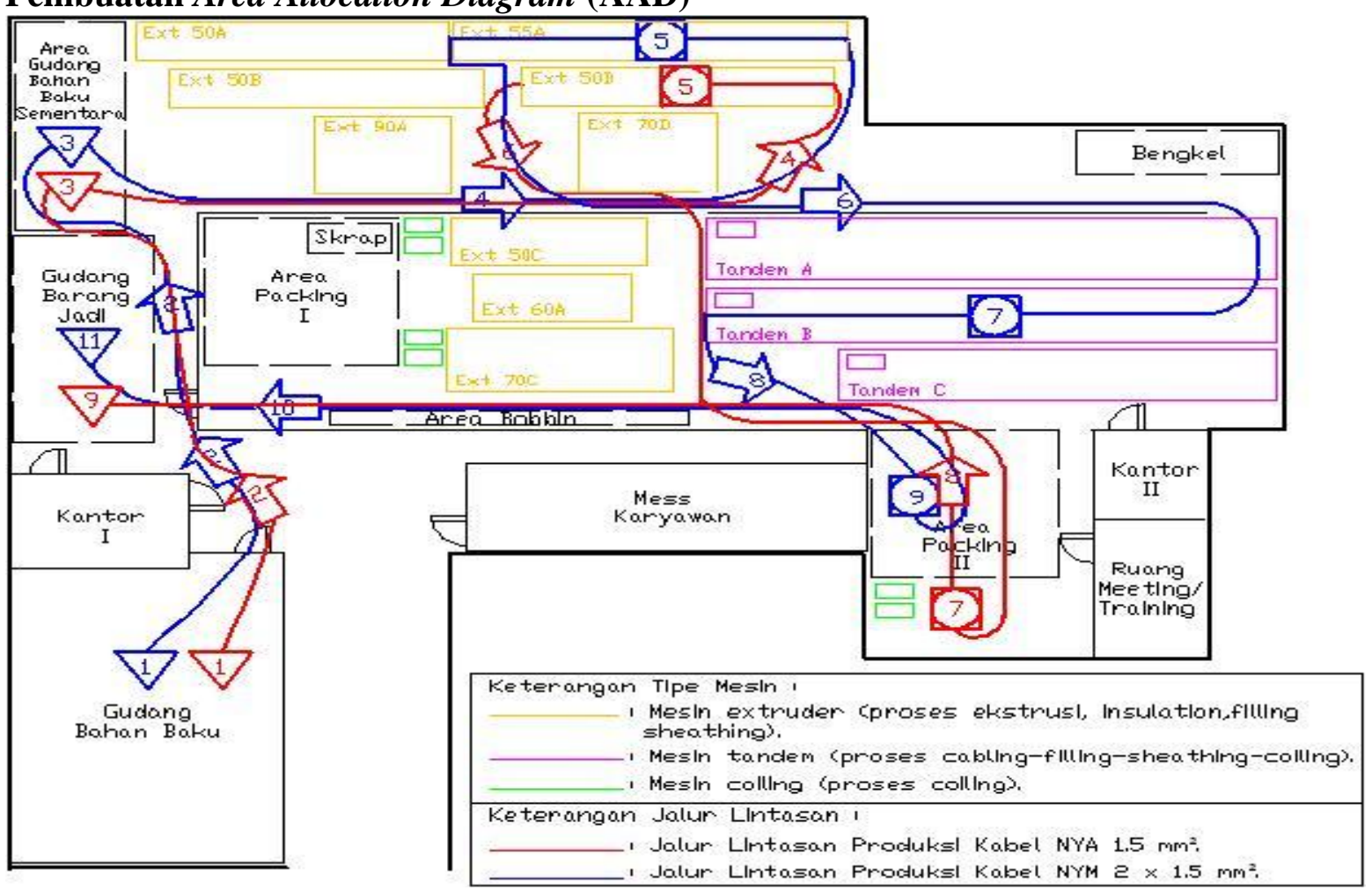

Gambar 6. Diagram Aliran Kabel NYA dan Kabel NYMpada Tata Letak Aktual 
Dasar dari pembuatan AAD adalah ARD yang dibuat dengan tujuan agar dapat diketahui susanan mesin berdasarkan pada hubungan keterkaitan antarmesin.Berdasarkan perancangan AAD terpilih yaitu AAD inflow kabel NYM, maka rancangan aliran pemindahan bahan yang di usulkan menggunakan pola melingkar(circular).Pada Gambar 6 dan Gambar 7 dapat dilihat perbandingan antara tata letak dan jalur lintasan tata letak pabrik awal dan tata letak pabrik yang baru.

Perubahan tata letak pabrik yang dilakukan dari tata letak awal ke tata letak usulan mampu meminimalisasi jarak dan biaya pemindahan bahan.Jarak pemindahan bahan pada tata letak awal sebesar 188 meter dan pada tata letak usulan sebesar 91.5 meter.Sedangkan biaya pemindahan bahan pada tata letak awal sebesar Rp 66.706,92 dan pada tata letak usulan sebesar Rp 18.962,03. Dengan kata lain, terjadi penurunan jarak pemindahan bahan sebesar $51 \%$ dan penurunan biaya pemindahan bahan sebesar $72 \%$.

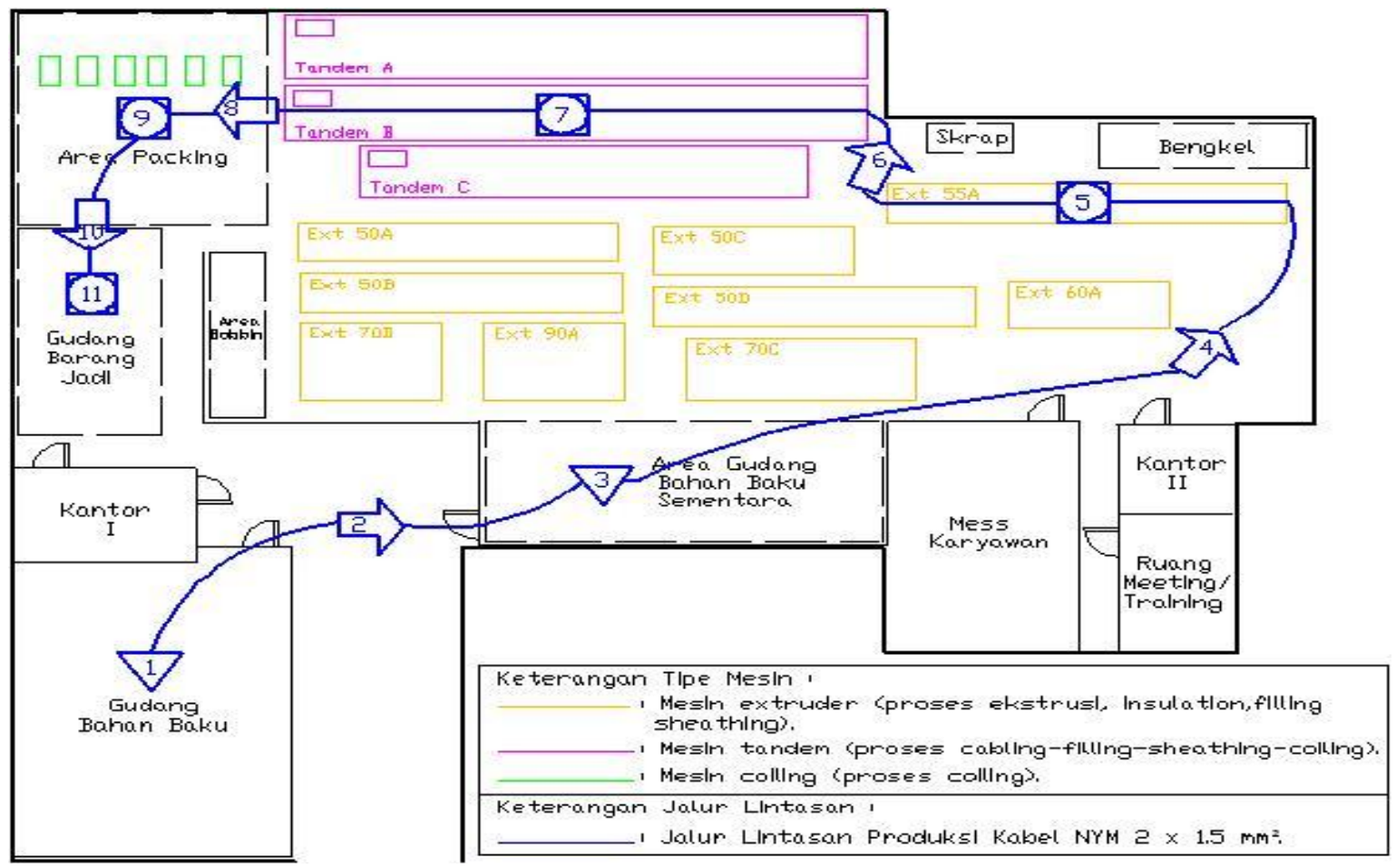

Gambar7.Diagram Aliran Kabel NYM pada Tata Letak Pabrik Usulan

\section{Pembuatan Material Handling Evaluation Sheet (MHES)}

Hasil MHES yang dibuat berdasarkan hasil rancangan AAD adalah total jarak pemindahan bahan per hari adalah 91.5 meter, sedangkan total biaya pemindahan bahan per hari adalah sebesar Rp 18.962,03.

Analisa perancangan ulang tata letak pabrik dilakukan dengan membandingkan antara tata letak pabrik awal dan tata letak pabrik yang baru, dimana nantinya akan terlihat seberapa besar pengaruh perbaikan yang diberikan tata letak baru sehingga layak untuk dijadikan usulan agar dapat digunakan oleh perusahaan. Analisa yang dilakukan terdiri dari analisa luas lantai produksi, analisa MHPS, analisa ARC, analisa ARD, analisa AAD, analisa MHES, dananalisa pemilihan tata letak pabrik.

Pada analisa pemilihan tata letak pabrik dijabarkan hasil perbandingan antara MHPS awal dan MHES inflow seperti terlihat pada Tabel 6berikut ini. 
Tabe16. Perbandingan MHPS Awal dan MHES InflowKabel NYM

\begin{tabular}{lcc}
\hline Tata Letak & $\begin{array}{c}\text { Total Jarak per 1 Kali Pemindahan } \\
\text { Bahanyaitu 106 roll Kabel } \\
\text { (meter) }\end{array}$ & $\begin{array}{c}\text { Total Biaya Pemindahan Bahan } \\
\text { per Hari yaitu 3,728.64 roll Kabel } \\
(\mathrm{Rp})\end{array}$ \\
\hline MHPS Awal & 188 meter & $66.706,92$ \\
MHES Inflow & 91.5 meter & $18.962,03$ \\
\hline
\end{tabular}

Tabel perbandingan MHPS awal dan MHES inflowdi atas menunjukkan bahwa total biaya pemindahan bahan MHES inflow lebih kecil dibandingkan total biaya pemindahan bahan MHPS awal. Maka rancangan tata letak berdasarkan AAD inflow dapat ditetapkan sebagai usulan terbaik bagi PT. XYZdengan total penurunan jarak pemindahan bahan sebesar $51 \%$ dan penurunan biaya pemindahan bahan sebesar $72 \%$.

Tahap terakhir merupakan tahap pembuatan simulasi proses produksi rancangan tata letak awal dan tata letak usulandengan menggunakan software ProModel. Tujuan pembuatan simulasi ini adalah untuk melihat sejauh mana perbedaan total waktu operasi dan pemindahan bahan di antara penerapan tata letak awal dan tata letak usulan.Pembuatan simulasi diperlukan untuk mengetahui jalannya suatu sistem tanpa mempengaruhi jalannya sistem tersebut.Prosedur perancangan dan pengembangan simulasi dilakukan untuk meningkatkan efisiensi kerja perancangan pemodelan dan efektifitas output simulasi terhadap sistem yang sesungguhnya.Untuk kepentingan perbandingan tata letak pada sistem yang nyata, maka simulasi proses produksi kabel NYM yang dibuat terdiri dari simulasi pada tata letak pabrik awal dan simulasi pada tata letak pabrik usulan.

Berikut pada Gambar 8 dan Gambar 9 dapat dilihat screen shot simulasi proses produksi kabel NYM pada tata letak pabrik awal dan tata letak pabrik usulan.

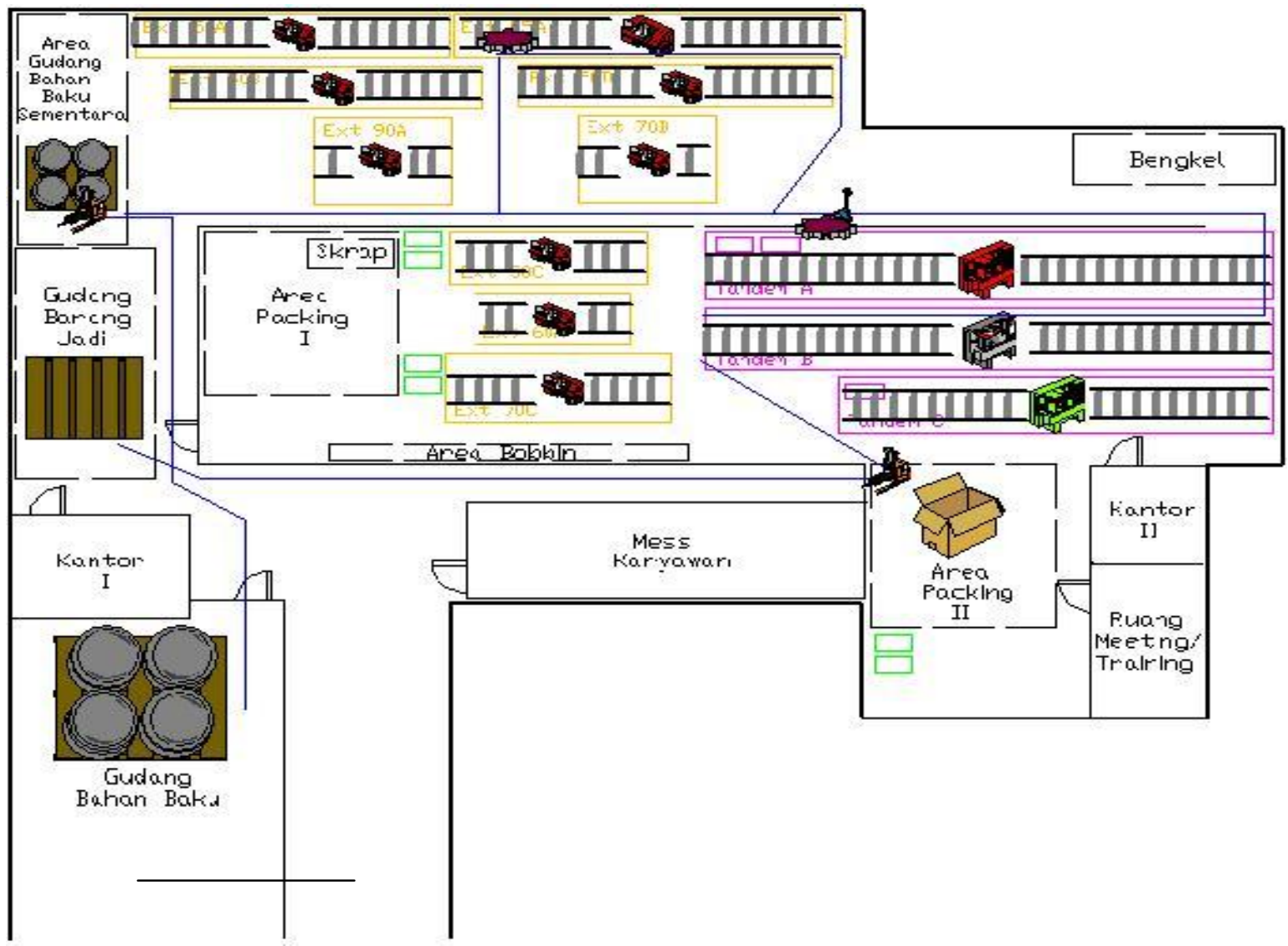

Gambar 8.Screen Shot Simulasi Proses Produksi Pada Tata Letak Pabrik Awal 


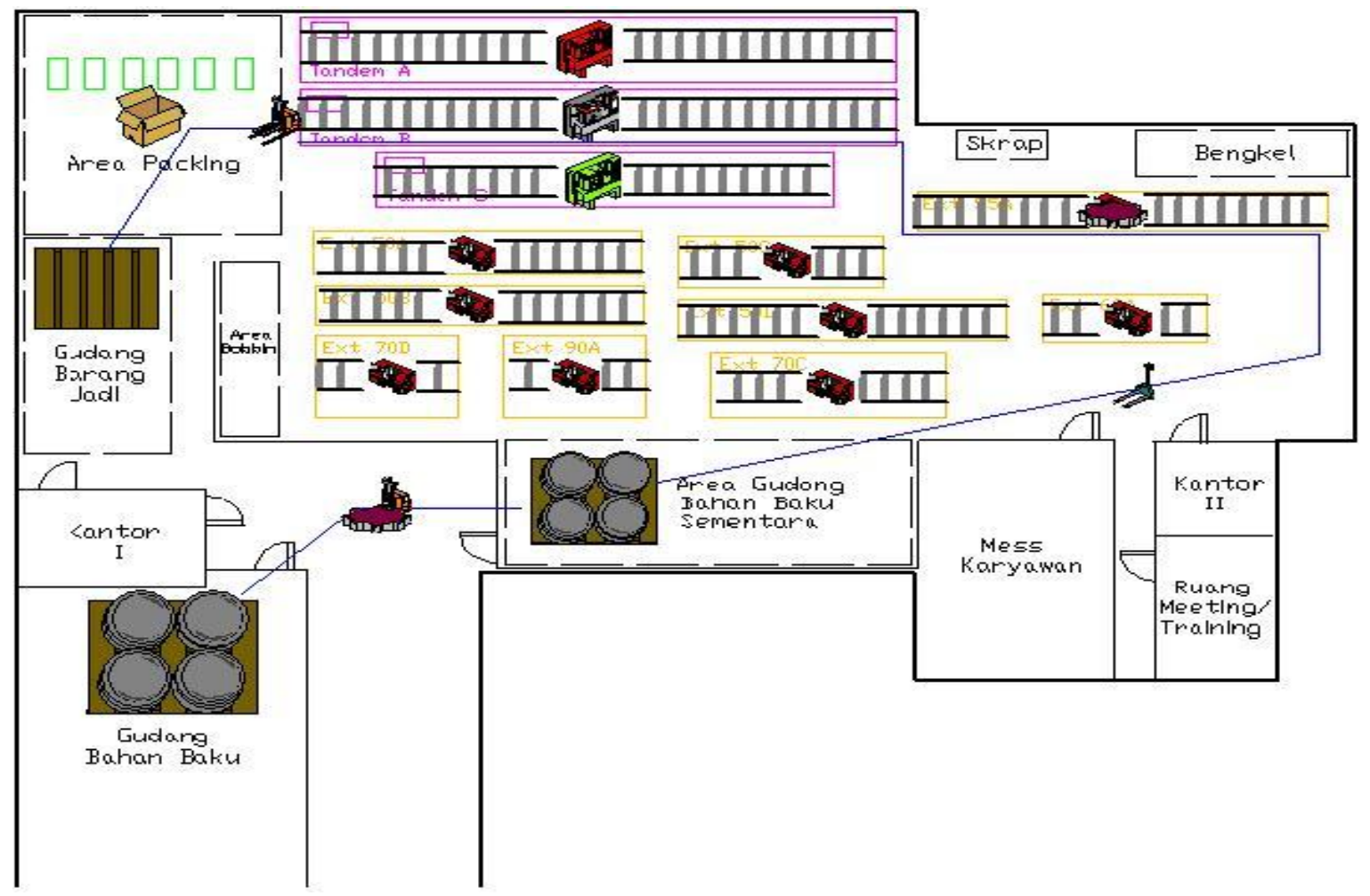

Gambar 9.Screen Shot Simulasi Proses Produksi Pada Tata Letak Pabrik Usulan

KESIMPULAN

Berdasarkan pembuatan ARD, rancangan tata letak pabrik yang dipilih untuk digunakan adalah AAD inflowkabel NYM $2 \times 1.5 \mathrm{~mm}^{2}$ dengan total jarak dan biaya pemindahan bahan yang minimal, serta efisien.Perubahan tata letak pabrik yang dilakukan dari tata letak awal ke tata letak usulan mampu meminimalisasi jarak dan biaya pemindahan bahan.Jarak pemindahan bahan pada tata letak awal sebesar 188 meter dan pada tata letak usulan sebesar 91.5 meter.Sedangkan biaya pemindahan bahan pada tata letak awal sebesar Rp 66.706,92 dan pada tata letak usulan sebesar Rp 18.962,03. Dengan kata lain, terjadi penurunan jarak pemindahan bahan sebesar $51 \%$ dan penurunan biaya pemindahan bahan sebesar $72 \%$. Selain itu, berdasarkan hasil report dari running 3 roll kabel NYM 2 x $1.5 \mathrm{~mm}^{2}$ pada masing-masing model simulasi tata letak pabrik awal dan tata letak pabrik usulan, dihasilkan penurunan waktu proses produksi (waktu operasi dan waktu pemindahan bahan) yang signifikan yaitu sebesar $37 \%$ dari total waktu proses produksi 20.83 menit pada tata letak pabrik awal menjadi 13.20 menit pada tata letak pabrik usulan. Bagiperusahaan, diharapkan untuk mempertimbangkan penggunaan tata letak pabrik usulan hasil dari penelitian ini, sehingga jarak pemindahan bahan dapat di minimalisasi, pengeluaran biaya pemindahan bahan lebih ekonomis.

\section{DAFTAR PUSTAKA}

[1]. Apple, James M., 1990, Tata Letak Pabrik dan Pemindahan Bahan, Edisi ketiga, ITB, Bandung.

[2]. Tompkins, J. A., 1996, Facilities Planning, John Willey \& Sons, Inc., United States of America.

[3]. Heragu, S., 1997, Facilities Design, PWS Publishing Company, Boston. 
[4]. Djati, Bonett S. L., 2007, Simulasi, Teori, dan Aplikasinya, Penerbit CV. Andi Offset, Yoyakarta.

[5]. Han, K. H., Bae, S. M., dan Jeong, D. M., A Matrix Based Approach to the Facility Re-Layout Problem, International Journal of Mathematical Models in Applied Science. (On-Line).Tersedia di http://www.naun.org/multimedia/NAUN/m3as/ 2001157.pdf (28 Mei 2013).

[6]. Miftahol, Arifin, 2009, Simulasi Sistem Industri, Penerbit Graha Ilmu, Yogyakarta.

[7]. Moengin, P. \& Putra, W. H., 2011, Penggunaan Simulasi Tata Letak Lantai Produksi Untuk Meminimasi Waktu Produksi dan Biaya Penanganan Material, Proceeding Seminar Nasional Teknik Industri \& Kongres BKSTI VI 2011.

[8]. Muther, R., 1955, Practical Plant Layout, Mc. Graw-Hill Inc., New York.

[9]. Purnomo, H., 2004, Perencanaan dan Perancangan Fasilitas, Cetakan pertama, Graha Ilmu, Yogyakarta.

[10]. Rao, R. V. \& Singh, D., 2012, Weighted Euclidean Distance Based Approach as a Multiple Attribute Decision Making Method for Plant or Facility Layout Design Selection, InternationalJournal of Industrial Engineering Computations. (OnLine).Tersedia di http://www/growingscience.com/ijiec/Vol13/IJIEC 2-12 23.pdf(28 Mei 2013).

[11]. Sule, Dr., 1994, Manufacturing Facilities, Location, Planning, and Design, PWS Publishing Company, Boston. 